\title{
INFLUENCE OF SOCIAL NETWORKS ON THE SUPPORTERS COMMUNITIES IN BULGARIA IN THE 2020/2021 SEASON
}

\author{
Hristina Yordanova, Minko Pondev \\ National Police General Directorate, National Centre for Security of Sport Events (Bulgaria)
}

\begin{abstract}
The development of technology and the transformation of the Internet into a dominant channel of communication have led to intense and diverse changes in the behavior of moderate and extreme supporters of sports teams. The report presents a brief overview of the characteristics of the communities of supporters in Bulgaria: profile, structure and dynamics of formal and informal fan organizations throughout the country and abroad. The global pandemic and the closure of sports facilities have led to an intensification of the importance of cyberspace as a substitute for real events and phenomena. This report focuses on the features and dynamics of open and closed fan groups on social networks. For this purpose, 150 pages of organizations and groups of supporters of the most active communities in Bulgaria were studied through the method of content analysis. The report presents a brief overview of the socio-psychological characteristics of fan communities and makes a typology of groups and pages in the Bulgarian virtual space by deriving four main types with their basic characteristics: common pages, national groups, regional factions and leaders' pages. The analysis focuses on their mechanisms of influencing the attitudes and behavior of both extreme and moderate supporters, through identified behavioral patterns online and live in the relatively short period of attending sporting events.

Keywords: typology of online fan groups; extreme supporters; fan factions; behavioral patterns online
\end{abstract}

\section{Introduction}

The globalization and development of Internet technologies have an indisputable impact on the way supporters' communities operate both on individual and group level. This process is happening simultaneously and gradually with technological progress over the last 30 years but in 2020/2021 season it has become an increasingly visible and structurally defining phenomenon in terms of behavior. This report will focus on the specifics of this phenomenon in Bulgarian country and will present conclusions based on the analysis of the content of fan pages on 
Facebook and ither social neworks of football clubs with numerous supporters, online and offline reactions of fans involved in this model of communication. The topic of football in social networks and fan club websites has been the subject of research by Michailidou et al. since 2018, as well as a 2017 study made by Vale $\&$ Fernandes. The study covers a large number of respondents from UEFA league fans. These studies are important on the topic of football fans online, but the current study will look at the period during the COVID-19 pandemic, when fans were not in the stadium, but in front of computers.

\section{Overview of the specifics of the supporters' communities in Bulgaria: profile, structure and dynamics}

1. Scope of supporters comminities

Regarding the communities of supporters in our country two numerous groups of supporters of the two most popular Bulgarian clubs CSKA and "Levski" undoubtedly stand out, as these groups cover the entire country and have registered structures abroad (Europe and USA). An attempt to develop a transregional character of the supporters is observed at "Ludogorets" by structuring formal fan organizations outside Razgrad (Varna, Brussels, etc.), but these organizations are few in number as members.

The other clubs can be relatively concluded that they have a purely regional scope, which exacerbates the existing opposition of the extreme supporters of the same city (Plovdiv, Varna) or repeat a confrontation based on a regional principle (Vratsa, Montana, etc.). These fan groups are not very numerous, but this characteristic reflects on increasing group cohesion, control and discipline.

Among the smaller regional organizations can be noted those with a high status among the other supporters, regardless of belonging and supporting to another club (Pernik, Gorna Oryahovitsa).

\section{Structure of supporters' communities}

Regarding the structuring of fan communities in Bulgaria, three main models make an impression:

- A community characterized in structural terms by national and regional organizations with a clear hierarchy, territorial distribution and spheres of influence, the presence of strong formal and informal leadership. This type of community maintains optimal communication with the club management and does not display a public confrontation.

- A community that formally unites national and regional organizations and leaders, maintaining competitive relations, which in these environments and under opportune external conditions and incentives grow into more or less serious physical aggression. There is also a confrontation with the official club managements and attempts for informal managing of the clubs. This leads to distancing moderate supporters from fan activities and radicalizing the behavior of the organizations and members involved in and outside sports facilities. 
- A community of autonomous peer organizations. This type of structure is typical of organized supporters of clubs in the countryside, where fan factions develop on a neighborhood basis or on the basis of another unifying factor.

However, regardless of the model of structuring in all communities of supporters in Bulgaria, two types of organizations are distinguished: factions of extreme supporters (hooligans and ultras) of the respective team and fan clubs uniting moderate supporters.

\section{Dynamics of supporters' communities}

Factions, fan clubs (including officially registered), etc. supporters' organizations are not constant group units. Their formation, development and eventual closure depend on various factors, including: profile of members, development of the sports club, model of group management, external pressure and others. It is not possible to extract definite models regarding the development of organizations. For example, in Bulgaria, when a football club is relegated to a lower league, there is often a consolidation and restructuring of the mass of supporters (including the return of "more moderate"), in other communities there is entropy and cessation of activities. In the case of leadership factions, usually after the withdrawal of the leader/s for one reason or another, the group disintegrates. In some cities in the country, the activities of fan organizations may be limited by more active and aggressive supporters of an opposing club.

With regard to the external dynamics of the groups in recent years there have been trends of maintaining friendly/neutral or conflicting relationships with supporters of other teams both in the country and abroad. It is noteworthy, however, that this is also a dynamic, generational defined process. Cases have been identified in which adherents of newer generations demonstrate diametrically opposed to relationships already established between older generations. Supporter communities replicate traditional relations of opposition at the regional and local level, with the exception of those of CSKA and "Levski", in which the confrontation is maintained on a national level, regardless of local characteristics. In the last 10 years, there has been opposition between traditional clubs with many supporters and newly formed clubs, as their supporters are stigmatized as a common enemy and the object of negligent and mocking fan creativity.

Some of the Bulgarian supporters organized in extreme factions maintain close contacts with supporters of foreign football clubs (the so-called "brotherhood"):

- CSKA with Partizan (Belgrade, Serbia), Steaua (Bucharest, Romania), Milan (Milan, Italy), CSKA (Moscow, Russia);

- at "Levski" with Lazio (Rome, Italy);

- to "Botev" (Plovdiv) with Aris (Thessaloniki, Greece);

- of "Lokomotiv" (Plovdiv) with Napoli (Naples, Rome).

The "Brotherhood" is operationalized and manifested through mutual visits to important sports events and tournaments mainly in the field of team sports 
(including fan tournaments), providing support through official symbols of the host organization, organizing joint events, participation in joint groups in social networks, use of accessories (T-shirts, hats, etc.), in which the close relations between factions and clubs are displayed through symbols or text.

\section{METHODOLOGY}

In the present study the method of analysis of the content of fan pages, groups and channels of supporters in Bulgaria for the 2020/2021 season on Facebook and You Tube is applied. 150 Internet sources were studied, distributed as follows: 60 pages of CSKA Sofia supporters, 54 of "Levski" Sofia, 10 of "Botev" Plovdiv, 6 of "Lokomotiv" Plovdiv, 3 of "Beroe" Stara Zagora, 3 of "Minyor" Pernik, 1 of "Slavia" Sofia, 2 of "Lokomotiv" Sofia, 1 of "Pirin" Blagoevgrad, 1 of "Botev" Vratsa and 10 common pages. The choice is based on two main criteria: the degree of risk of the supporters and presence on social networks. The aim of the study is to examine the current state of the fan communities in Bulgaria in the context of the restrictions imposed by the global pandemic, and to identify the main mechanisms of influence on supporters exercised through social media.

The analysis of the dynamics of the activity of fan organizations in social networks is consistent with the condition that there is no objective method by which they can be statistically registered and in this sense the results should be perceived as a "snapshot" of accessible content. Some of the pages are public, others have a conspiratorial nature (mostly of extreme factions known for their illegal behavior).

\section{Results and Conclusions}

Based on the study, the following conclusions can be made:

\section{Typology of fan pages and channels \\ General pages}

Bulgarian fan pages usually follow already established international models, which are a reference for fans from all over the world, and the most successful ones are directly replicated with similar content in Bulgarian or translated materials (eg Ultras World, ULTRAS-TIFO.net, ultras-bulgaria). net, etc.). This type of pages and channels try to follow a neutral multiclub policy by publishing materials of an informative rather than evaluative or propagandistic nature. They usually have a public account, which makes them available for reading and commenting by absolutely all interested users. Below the publications there are invariably aggressive comments, which in a practically indefinable number of cases turn into virtual and real conflicts.

\section{Pages of national or influential regional fan organizations}

It is this type of pages that are defined as setting standards for online and offline behavior among followers. Through these channels the official ideology and policy of the entire mass of supporters are promoted, models of attitude and official 
behavior towards institutions, clubs, opponents' supporters, events are imposed. Thus e.g. at the apogee of the protests in 2020, supporters of certain football clubs, through the official fan pages, distinguished themselves from committing protests as a collective, expressing club affiliation, subject. Through these channels, activities and often funding campaigns are promoted. In these communities, where symbiotic relationships between club owners, reference leaders, and influential factions are identified, fan pages and groups are used to form club attitudes and behaviors in critical situations. Conversely, in the event of a confrontation with management or an internal conflict, these channels often spontaneously become a generator of additional tension, rumors and conflicts.

Usually this type of pages are open and public as they are "unspoken" official sources of information. The administrators of the pages are bound by the leadership of the factions and filter opinions and participants according to the group's policy.

\section{Pages of regional factions}

Usually the name of these pages includes the name and region of the fan organization, but whether it is open or closed, administrators allow members of other factions to participate. This type of pages are often used for instrumental purposes to organize group activities, with increased activity observed before major sporting events. Another type of common content is the dissemination of official club information and/or information concerning the national community of supporters.

\section{Personal pages of influential leaders}

All formal and informal leaders of supporters' factions maintain their personal pages but it is not possible to show a definite tendency whether they are public or limited. Some of the leaders purposefully use this channel in the context of the organization and the club and through them generate attitudes, opinions and behaviors among the followers. In other leaders, there are everyday ("household") profiles and pages in which information about personal events and positions on organizational topics are mixed spontaneously, which violates the "sacredness" of the leader. This type of online behavior also identifies a tendency to engage in personal and club conflicts.

\section{Mechanisms of influence on supporters}

The Internet and in particular social networks are actively used in the generating of behavioral patterns, especially among users in childhood and adolescence. Most often, short audiovisual forms (videos, photos, so-called "memes") with clear and easy-to-remember messages are used, which are internalized and transferred uncritically by users. Both the content and the visual layout are made in the established style of the club, which makes them easily recognizable for both supporters and opponents. Increased activity is observed before and after important sporting events by generating and distributing materials with specific content. In the conditions of holding sports events without an audience, the Internet 
production becomes a virtual substitute for choreography, which is the main means of expression of the fans.

In the process of forming behavioral models, the rational exchange of information must be analyzed, especially in the context of a pandemic and the inability of supporters to use face-to-face communication. This mechanism is most often used by club officials. In this way, the pages open for discussion become a kind of method for exploring the attitudes and opinions of supporters on topics critical to the teams.

Through the fan pages, groups and channels, direct events are organized participation in sports meetings, protest actions, fan tournaments, etc. Very often this format sets specific standards of behavior such as clothing, chanting, choreography, routes and more. In addition to achieving the organizational goals, this model of communication is informative in terms of interest and eventual attendance at the event.

The pages and groups in the social networks are actively used in order to form a certain (negative/positive) attitude not only to events, ideas, policies but also to specific reference persons for the supporters. By publicly discrediting or sacralizing people, the "live" attitude towards them is "reformatted". In this process, the socalled "influencers" take an active part among the supporters - influential people who are not formally associated with the club or factions, but have a high status in the community.

Personal data (photos, addresses, telephone numbers, family and friends, photos of personal communication) of persons identified as "enemies" - other supporters, club employees and mostly police officers - are published on social networks and specialized pages and profiles.

The overexposure of the use of pyrotechnics in social networks and the devaluation of the negative effects stimulates spontaneous attempts, especially by minors, to bring and ignite in sports facilities. Illegal sale of pyrotechnic articles is also carried out through closed groups.

With regard to antisocial behavior, especially in conditions of pandemic and quarantine, information on social networks is perceived as the only and indisputable source and authority for many individuals with a deviant profile. Virtual communication forms uncriticism of one's own behavior, depersonalizes the communication partner (s), exacerbates narcissistic and antisocial accentuations, which facilitates the commission of illegal acts from an extremely wide range from online harassment to live physical aggression.

It is a common practice to deliberately overexpose oneself before risky football matches, especially with a rival whose supporters have a history of physical clashes, shots of conflicts and fights, in order to accumulate negative attitudes and possibly provoke beatings.

Closed groups on social networks and forums are used as a medium to promote "victories" over rivals - wounded opponents, captured symbols (T-shirts, scarves 
and especially flags of factions), desecration of buildings and sports facilities and more.

In conclusion, it can be predicted that the role of social networks in the existence and functioning of fan communities will deepen and is likely to displace some traditional activities that require face-to-face communication. The pandemic and the measures taken worldwide accelerate this process and as a result new communities and relationships are formed in the virtual space, conflicts are generated, new associations of extreme supporters are created. Restrictions on attending sporting events have led to the emergence of "abstinence" on the part of supporters, which reflects on the dynamization of behavior, both online and "live".

However, the effects of the pandemic and social media impact on the behavior of outsiders at this stage can be seen as an intermediate outcome that will be modified depending on the duration of the restrictions.

\section{REFERENCES}

Michailidou, E., Gargalianos, D., Mavridis, G. \& Filippou, F., 2018. Social Media in Football: The Case of the Fan Page "Oscar_Embooba_Army", Choregia, 14. 39 - 48. DOI:10.4127/ch.2018.0134.

Vale, L. \& Fernandes, T., 2017. Social media and sports: driving fan engagement with football clubs on Facebook. Journal of Strategic Marketing, 26(1), $37-55$.

\section{Hristina Yordanova, Minko Pondev}

National Police General Directorate National Centre for Security of Sport Events 